\title{
Memória de trabalho, consciência fonológica e hipótese de escrita $* * * *$
}

\author{
Working memory, phonological awareness and spelling hypothesis
}

\author{
Gigiane Gindri* \\ Márcia Keske-Soares** \\ Helena Bolli Mota***
}

*Fonoaudióloga. Mestre em Distúrbios da Comunicação Humana pela Universidade Federal de Santa Maria. Endereço para

correspondência: Rua São Luis, 1087 - Apto. 401 - Porto Alegre - RS - CEP 90620-170

(fga.gigi@terra.com.br).

**Fonoaudióloga. Doutora em Lingüística Aplicada pela Pontifícia Universidade Católica do Rio Grande do Sul. Docente dos Cursos de Graduação e Especialização em Fonoaudiologia e de Mestrado em Distúrbios da Comunicação Humana da Universidade Federal de Santa Maria.

***Fonoaudióloga. Doutora em Lingüística Aplicada pela Pontifícia Universidade Católica do Rio Grande do Sul. Docente dos Cursos de Graduação e Especialização em Fonoaudiologia e de Mestrado em Distúrbios da Comunicação Humana da Universidade Federal de Santa Maria.

****Parte da Tese da Dissertação da Primeira Autora Realizada na Universidade Federal de Santa Maria Apresentada no Curso de Mestrado em Distúrbios da Comunicação Humana da Universidade Federal de Santa Maria.

Artigo de Pesquisa

Artigo Submetido a Avaliação por Pares

Conflito de Interesse: não

Recebido em 02.03.2006.

Revisado em 15.12.2006; 10.04.2007;

18.06.07; 27.07.2007.

Aceito para Publicação em 27.07.2007.

\begin{abstract}
Background: working memory, phonological awareness and spelling hypothesis. Aim: to verify the relationship between working memory, phonological awareness and spelling hypothesis in pre-school children and first graders. Method: participants of this study were 90 students, belonging to state schools, who presented typical linguistic development. Forty students were preschoolers, with the average age of six and 50 students were first graders, with the average age of seven. Participants were submitted to an evaluation of the working memory abilities based on the Working Memory Model (Baddeley, 2000), involving phonological loop. Phonological loop was evaluated using the Auditory Sequential Test, subtest 5 of Illinois Test of Psycholinguistic Abilities (ITPA), Brazilian version (Bogossian \& Santos, 1977), and the Meaningless Words Memory Test (Kessler, 1997). Phonological awareness abilities were investigated using the Phonological Awareness: Instrument of Sequential Assessment (CONFIAS - Moojen et al., 2003), involving syllabic and phonemic awareness tasks. Writing was characterized according to Ferreiro \& Teberosky (1999). Results: preschoolers presented the ability of repeating sequences of 4.80 digits and 4.30 syllables. Regarding phonological awareness, the performance in the syllabic level was of 19.68 and in the phonemic level was of 8.58. Most of the preschoolers demonstrated to have a pre-syllabic writing hypothesis. First graders repeated, in average, sequences of 5.06 digits and 4.56 syllables. These children presented a phonological awareness of 31.12 in the syllabic level and of 16.18 in the phonemic level, and demonstrated to have an alphabetic writing hypothesis. Conclusion: the performance of working memory, phonological awareness and spelling level are inter-related, as well as being related to chronological age, development and scholarity. Key Words: Working Memory; Phonological Awareness; Spelling Hypothesis; Preschool; First Grade.
\end{abstract}

\section{Resumo}

Tema: memória de trabalho, consciência fonológica e hipótese de escrita. Objetivo: verificar a relação entre a memória de trabalho, a consciência fonológica e a hipótese de escrita em alunos de pré-escola e primeira série. Método: a amostra foi composta de 90 alunos da rede estadual de ensino que apresentavam desenvolvimento lingüístico típico. Destes, 40 alunos eram da pré-escola, com idade média de seis anos e cinco meses, e 50 eram da primeira série, com idade média de sete anos e dois meses. A amostra selecionada foi submetida à avaliação das habilidades de memória de trabalho com base no Modelo de Memória de Trabalho de Baddeley (2000), envolvendo o componente fonológico. O componente fonológico foi avaliado através do subteste cinco, Memória Seqüencial Auditiva, do Teste Illinois de Habilidades Psicolinguísticas (ITPA), adaptação brasileira realizada por Bogossian e Santos (1977), e da Prova de Repetição de Palavras sem Significado, elaborado por Kessler (1997). As habilidades de consciência fonológica foram estudadas a partir do teste Consciência Fonológica: Instrumento de Avaliação Seqüencial (CONFIAS), elaborado por Moojen et al. (2003), considerando tarefas de consciência silábica e fonêmica. A escrita foi caracterizada conforme a proposta de Ferreiro e Teberosky (1999). Resultados: os pré-escolares apresentaram capacidade de repetir seqüências de 4,80 dígitos e 4,30 sílabas; em consciência fonológica, o desempenho em nível de sílabas foi de 19,68 e 8,58, em nível de fonemas; e hipótese de escrita pré-silábica, em sua maioria. Os alunos de primeira série repetiram, em média, seqüências de 5,06 dígitos e 4,56 sílabas, apresentaram desempenho de 31,32, em consciência fonológica em nível de sílabas, e 16,18, em nível de fonemas; e hipótese alfabética de escrita. Conclusão: o desempenho em memória de trabalho, consciência fonológica e nível de escrita se inter-relacionam, bem como estão relacionados com a idade cronológica, a maturidade e a escolaridade.

Palavras-Chave: Memória de Trabalho; Consciência Fonológica; Hipótese de Escrita; Pré-escola; Primeira Série. 


\section{Introdução}

A memória de trabalho, a consciência fonológica, a rapidez e a precisão no acesso ao léxico mental são habilidades do processamento fonológico. Segundo Torgesen et al. (1994) e Capovilla et al. (2004), elas se referem à forma como as informações são processadas, armazenadas e utilizadas. O processamento fonológico é considerado uma habilidade necessária à alfabetização e facilitadora da aprendizagem da leitura e da escrita (Torgesen et al., 1994; Demont, 1997).

Segundo Miller (1956), a memória de trabalho é limitada quanto à capacidade de armazenamento imediato de informação. Fica, pois, em evidência, que este sistema de memória apresenta limitação quanto ao tempo, mas pode ser mantido, se for ativado pela repetição de manutenção ou pela transferência à memória de longo prazo. Tarefas que envolvem habilidades fonológicas, como nomear letras e objetos, relembrar sentenças faladas e ouvir histórias e rimas infantis, promovem as habilidades de memória (Mann e Llberman, 1984; Santos e Siqueira, 2002). Desta forma, elas podem facilitar a habilidade de representar inputs fonologicamente (consciência fonológica), na memória de trabalho.

A memória de trabalho é designada como um sistema capaz de reter e manipular temporalmente a informação, enquanto participa de tarefas cognitivas como raciocínio, compreensão e aprendizagem (Adams e Gathercole, 1995; Alloway et al., 2004).

Baddeley (2000) acrescentou ao modelo, que compreende uma central executiva, dois sistemas de suporte responsáveis pelo arquivamento temporário e pela manipulação de informações - um de natureza visuo-espacial e outro de natureza fonológica -, o quarto componente, denominado buffer episodic. Este corresponde a um sistema de capacidade limitada, no qual a informação evocada da memória de longo prazo se torna consciente, permitindo lidar com a associação entre as informações mantidas no sistema de suporte e promover sua integração com informações da memória de longo prazo.

A alça fonológica processa as informações verbalmente codificadas. Para isso, conta com dois componentes: a memória fonológica de curto prazo e a realimentação subvocal. O componente fonológico da memória de trabalho, também chamado de loop fonológico, realiza a estocagem de material verbal, que se deteriora rapidamente. A realimentação subvocal ou loop articulatório permite resgatar as informações verbais em declínio e manter o material na memória. Ela sofre influência de extensão e freqüência do material verbal e inicia seu desenvolvimento a partir dos seis anos de idade (Baddeley, 2003).

Parece haver indícios que a memória de trabalho tem um importante papel nas tarefas que solicitam a consciência fonológica (Alloway et al., 2004; Morgado, 2005). Isto parece ocorrer, porque, durante a realização de uma tarefa desta natureza, é necessário que o material verbal seja mantido na memória de trabalho, a fim de haver sucesso na resolução da tarefa solicitada.

O presente trabalho está circunscrito ao componente fonológico da memória de trabalho, que é um dos aspectos mais estudados.

Ao investigar a capacidade de armazenamento memória de trabalho, Miller (1956) constatou que a capacidade de manutenção e durabilidade é frágil e limitada a, aproximadamente, um número de partículas diferentes, entre cinco e nove. Gathercole (1995) observara que ela diz respeito a um curto período de tempo, durante o qual se precisa registrar e manter a informação estável, para que seja compreendida e utilizada, tendo a capacidade de codificar, em média, de sete a oito itens distintos e de reter a informação, durante um período de tempo limitado.

As habilidades de memória tendem a melhorar com o avanço da idade (Gathercole, 1995) devido ao processo maturacional (Hulme, Thomson, Lawrence, 1984; Baddeley, 2003) e à aprendizagem (Etchepareborda e Abad-Mas, 2005; Gindri, KeskeSoares, Mota, 2005).

$\mathrm{Na}$ avaliação do componente fonológico, tarefas de repetição de seqüência dígitos - digit span - e de sílabas de palavras sem significado, também chamadas de não-palavras, são usuais. Vários autores afirmam que os resultados destas tarefas podem ser comparados (Adams e Gathercole, 1995; Kessler, 1997; Baddeley, 2003). A repetição de palavras sem significado, segundo Gathercole (1995), avalia com maior precisão o loop fonológico, uma vez que ele é desprovido das influências lexicais - fonologia, semântica e sintaxe.

A consciência fonológica é definida como a capacidade para refletir sobre a estrutura sonora da fala bem como manipular seus componentes estruturais, trata-se, portanto, da capacidade de pensar e operar sobre a linguagem como um objeto (Coimbra, 1997; Demont, 1997; Morais et al., 1998; Moojen et al., 2003).

Cielo (2002) destaca que a consciência fonológica desenvolve-se espontânea e automaticamente, de modo natural, sem demandar atenção especial durante a comunicação, embora possa ser acionada quando há necessidade de se ter controle sobre a língua. Isto 
ocorre para que o indivíduo possa se concentrar na forma em detrimento ao conteúdo, seja na fala, seja na escrita. Magnusson (1990) afirma que o papel da consciência fonológica é mais evidente para o desenvolvimento da linguagem escrita do que para a fala. Gombert (1992) e Flores (1992) concordam que, para a aquisição da língua oral e escrita, esta habilidade é importante.

Yavas (1989) destaca que a consciência fonológica mostra melhora com a idade, embora alguns níveis requeiram contato com a instrução alfabética. Morais et al. (1998) e Moojen et al. (2003) consideram apropriada a hipótese de uma relação de causalidade recíproca entre o aprendizado do código escrito e o desenvolvimento das habilidades de consciência fonológica. Maluf e Barrera (1997), a partir da perspectiva psicogenética, mostraram haver correlação significativa entre os níveis de consciência fonológica e de aquisição da linguagem escrita, independente do gênero. Capellini e Ciasca (2000) e Santamaria et al. (2004) pontuam que a consciência fonológica pode ser desenvolvida também em concomitância com o processo de alfabetização.

A introdução de um sistema alfabético auxilia no desenvolvimento da consciência fonológica, ressaltando-se sua importância para as habilidades fonêmicas (Demont, 1997; Capovilla et al., 2004).

A consciência fonológica se desenvolve em um continuum de padrões de complexidade, em etapas evolutivas sucessivas, não necessariamente lineares, integrando um processo continuado. Roazzi e Dowker (1989) explicam que os resultados de desempenho, nas tarefas de consciência fonológica, diferenciam-se pelo grau de experiência cognitiva que cada uma exige, isto é, pela capacidade de processamento de informação que solicitam.

As habilidades de consciência silábica precedem à capacidade de a criança tomar os fonemas como unidades lingüísticas (Magnusson, 1990; Capellini e Ciasca, 2000). Considerando-se as diferenças quanto às dificuldades observadas entre a análise silábica e a análise fonêmica, Coimbra (1997) sugere que as habilidades de síntese, tanto silábica quanto fonêmica, aparecem primeiro, antecedendo as habilidades de segmentação e de manipulação silábicas e fonêmicas, que são intermediárias. A última habilidade a se desenvolver é a de transposição, tanto de sílabas quanto de fonemas.

Vários estudos apontam que crianças que têm consciência dos fonemas avançam de forma mais fácil e produtiva na escrita e na leitura (Santos e Navas, 2002; Ferreiro, 2004), enquanto as que não têm estas habilidades correm risco de não conseguirem aprender a ler e a escrever (Capellini e
Ciasca, 2000; Santamaria et al., 2004). As atividades de consciência fonológica contribuem para melhorar o desempenho da criança, durante a fase inicial do aprendizado da leitura, repercutindo, positivamente, em estágios mais avançados do processo, assim como o treinamento e a terapia são fatores que facilitam a aquisição do código escrito (Lazarrotto e Cielo, 2002; Capovilla et al., 2004).

O processo de aquisição da língua escrita ultrapassa o automatismo. Santos e Navas (2002) acrescentam que a escrita é uma forma de expressão da linguagem, sendo uma das suas funções principais a comunicação simbólica. As habilidades necessárias para a aquisição da escrita dependem do nível em que o processo se encontra, o qual se relaciona a diferentes fatores internos e externos ao sujeito (Dockrell e McShane, 1997; Morais et al., 1998; Etchepareborda e Abad-Mas, 2005).

Ferreiro e Teberosky (1999) propõem que a construção da escrita é resultante de um processo gradual, em que são contrastadas situações de desenhar com situações de escrever, experimentação e experiências. Quatro hipóteses de escritas fundamentais são definidas: présilábica, silábica, silábica-alfabética e alfabética.

Na hipótese pré-silábica, a criança acredita que escrever é desenhar o objeto. Aparecem tentativas de correspondência entre a escrita e o objeto referido (realismo nominal). Outras características são: os diferentes estilos, utilizados nesta fase inicial da escrita; as problemáticas quanto à orientação espacial da escrita; a dificuldade em estabelecer diferença entre as atividades de escrever e desenhar (ora a escrita é representada por letras, ora por desenhos, ou por ambos); a quantidade mínima de caracteres exigidos; a variedade desses caracteres. Desta maneira, cada um só pode interpretar a sua própria escrita e não a dos outros. A maioria das crianças, na faixa dos seis anos, faz corretamente a distinção entre texto e desenho, sabendo que o que se pode ler é aquilo que contém letras. Algumas, no entanto, ainda persistem na hipótese de que se pode ler tanto as letras quanto os desenhos. Respeitam duas exigências básicas: a quantidade de letras (nunca inferior a três) e a variedade entre elas (não podem ser repetidas).

A hipótese silábica tem como principal característica a tentativa de associar um valor sonoro a cada uma das letras que compõem a escrita. Nesta etapa, a criança passa pelo período de maior importância evolutiva, em que cada letra vale por uma sílaba. A criança avança muito qualitativamente, pois supera a correspondência global entre a forma escrita e a expressão oral, para fazer a correspondência entre as partes do texto, que são as letras, e as partes das 
impressões orais, representadas pelo recorte silábico do nome. A criança considera que a escrita representa as partes sonoras da fala. Cada grafia traçada corresponde a uma sílaba pronunciada, podendo ser usadas letras ou outro tipo de grafia.

A transição entre a hipótese silábica e a alfabética caracteriza a hipótese silábico-alfabética. A criança abandona a primeira e descobre que necessita analisar outras possibilidades de escrita. Nesta etapa, duas características importantes da escrita anterior tendem a desaparecer: a de quantidade mínima (uma exigência interna da própria criança) e a de variedade de caracteres (o número mínimo de grafias). A criança, então, começa a perceber que escrever é representar, progressivamente, as partes sonoras das palavras, ainda que não o faça corretamente.

A hipótese alfabética é a etapa final da evolução desta psicogênese. Ao chegar nesta fase, a criança compreende que cada um dos caracteres da escrita corresponde a valores sonoros menores que a sílaba. Realiza, sistematicamente, a análise sonora dos fonemas das palavras que necessita escrever.

Santos e Navas (2002) propõem que a linguagem escrita tem relação íntima com a oral. Apesar de ser relativamente fácil, para a maioria das crianças, aprender a ler e a escrever, as habilidades lingüísticas e cognitivas básicas, necessárias para que a aprendizagem possa ocorrer, são numerosas e complexas. É aceito que as habilidades da linguagem falada constituem a base para a aquisição da leitura e da escrita(Flores, 1992; Demont, 1997; Ferreiro, 2004).

As atividades cognitivas - como a aprendizagem formal de leitura e escrita, a compreensão e o raciocínio - são realizadas com aporte da memória de trabalho. $\mathrm{O}$ processo de ensino-aprendizagem solicita constantemente o uso da memória (Morgado, 2005; Etchepareborda e Abad-Mas, 2005).

O conhecimento alfabético requer uma série de habilidades fonológicas especializadas. Inicialmente, a consciência fonológica, que é a capacidade de detectar sons de fala similares nas palavras, permite às crianças representar os segmentos de som na linguagem escrita. Aprender a ler, no entanto, solicita tipos mais avançados de consciência fonológica. À medida que as crianças tomam consciência de tipos diferentes de unidades fonológicas, ou seja, de sílabas, rimas e fonemas, e aprendem a manipulá-las, há concomitante evolução da leitura (Morais et al., 1998; Santamaria et al. 2004).

As implicações educacionais da relação entre memória de trabalho, consciência fonológica e escrita são bastante expressivas (Santos e Siqueira, 2002), embora atualmente os programas de alfabetização ainda dêem pouca importância ao uso das habilidades metafonológicas como auxiliares para a aquisição do código escrito (Capovilla et al., 2004).

Há estudos relacionando a memória de trabalho com a escrita, a consciência fonológica com a escrita, bem como a memória de trabalho com a consciência fonológica, mas não o cruzamento dos três aspectos. Neste sentido, esta pesquisa tem por objetivo verificar a relação entre a memória de trabalho, a consciência fonológica e a hipótese de escrita de alunos de préescola e primeira série, da rede estadual de ensino da zona urbana de Santa Maria - Rio Grande do Sul.

\section{Método}

Inicialmente a pesquisa foi submetida ao Comitê de Ética em Pesquisa do Centro de Ciências da Saúde, da Universidade Federal de Santa Maria, tendo sido o projeto aprovado sob o número 097/04.

Nas escolas visitadas da zona urbana que concordaram com a realização da pesquisa em suas dependências, os responsáveis assinaram o Termo de Consentimento Informado Institucional.

Posteriormente, após esclarecimentos sobre a pesquisa, foi solicitado o consentimento dos pais e/ou responsáveis através da assinatura do Termo de Consentimento Livre e Esclarecido.

Realizou-se, para delimitação da amostra, estudo estatístico apenas com os alunos autorizados. Devido às dificuldades metodológicas quanto ao consentimento para a realização da pesquisa, muitos alunos deixaram de ser incluídos, por não possuírem autorização dos responsáveis, embora a escola desejasse as avaliações. Isto determinou uma amostra por conveniência.

Utilizando-se de amostragem aleatória simples em cada grupo, foram selecionados, através de sorteio, efetuado na presença de um juiz, os alunos autorizados da pré-escola e da primeira série. Este procedimento foi repetido até que, preenchendo as variáveis necessárias, atingiu-se o número esperado para estudo significativo estatisticamente e representativo das sete áreas geográficas da zona urbana de Santa Maria - Rio Grande do Sul.

Os alunos que fizeram parte do estudo preencherem os seguintes requisitos: ter autorização dos pais e/ou responsáveis para a participação na pesquisa; apresentar desenvolvimento neuropsicomotor normal; apresentar desenvolvimento típico de fala; ter ausência de repetência em seu histórico escolar; não apresentar deficiência auditiva ou visual; não apresentar suspeita de alterações psicológicas e neurológicas; não apresentar alterações fonoaudiológicas, como dificuldade de aprendizagem, retardo de linguagem, 
desvio fonético e/ou fonológico e respiração oral; não estar em ou ter antecedente de terapia fonoaudiológica; não estar em atendimento psicopedagógico, reforço escolar ou acompanhamento pedagógico.

Contou-se com uma amostra de noventa alunos, sendo quarenta de pré-escola e cinqüenta de primeira série. A média de idade dos alunos da pré-escola foi de seis anos e cinco meses e dos alunos de primeira série, de sete anos e dois meses. Quanto ao sexo, na pré-escola havia catorze alunos do sexo masculino e vinte e seis do feminino, enquanto na primeira série havia vinte e seis do sexo masculino e vinte e quatro do feminino.

Os procedimentos constantes para o estudo foram realizados no ambiente escolar, em sala silenciosa, com cada aluno individualmente, durante o mesmo período de suas aulas. As avaliações foram realizadas, a viva voz, em intensidade de conversação, pela pesquisadora, durante o mesmo período letivo na pré-escola e primeira série. Ainda foram realizados os devidos registros, com anotações nos protocolos específicos.

A fim de conhecer a história individual e verificar os quesitos necessários para a participação na pesquisa, realizou-se a anamnese fonoaudiológica abordando aspectos relacionados a desenvolvimento neuropsicomotor, de linguagem e fala; voz; hábitos orofaciais; antecedentes fisiopatológicos e familiares; escolarização e aprendizagem.

A triagem fonoaudiológica foi realizada a fim de verificar se a criança podia fazer parte do estudo e envolveu linguagem, aspectos da motricidade oral e audição. A linguagem foi observada de maneira informal, utilizando a figura "circo" proposta por Hernandorena e Lamprecht (1997), através de fala espontânea. Nessa avaliação, foram observados os componentes fonológico, semântico, sintático e pragmático da linguagem. Na oportunidade, ainda se observaram fala, fluência e voz. Os alunos sem alteração no desenvolvimento da linguagem oral e, portanto, com desenvolvimento lingüístico típico, foram selecionados.

No que concerne à motricidade oral, foram observados aspecto, tônus, postura e mobilidade dos órgãos fonoarticulatórios e as funções neurovegetativas (Marchesan, 2005).

Para excluir possíveis alterações auditivas, realizou-se screenig auditivo, precedido por meatoscopia. O screenig auditivo foi realizado com Audiômetro Pediátrico Interacoustics PA2, com tons puros, nas freqüências de $500 \mathrm{~Hz}, 1 \mathrm{KHz}, 2 \mathrm{KHz}$ e $4 \mathrm{KHz}$, e intensidade de referência de $20 \mathrm{~dB}$ NA, mantendo distância aproximada de 50 centímetros do pavilhão auricular, como recomendado pelo padrão ANSI, 1969 (Northern e Downs, 1989).

Os alunos com suspeita de alterações de linguagem, motricidade oral, audição, neurológicas, oftalmológicas e psicológicas foram encaminhados para avaliações complementares (otorrinolaringológica, audiológica, neurológica, oftalmológica e psicológica) e excluídos da pesquisa.

Os alunos selecionados para o estudo foram submetidos às avaliações específicas de hipótese de escrita, do componente fonológico da memória de trabalho e de consciência fonológica.

\section{Avaliação da hipótese de escrita}

Na avaliação da hipótese de escrita, solicitouse a escrita do próprio nome e de uma amostra de palavras e frase, utilizando-se o proposto pelo teste CONFIAS - o aluno escreve "castelo", "esqueleto" e "O fantasma abriu a porta" ( Moojen et al., 2003). A fim de motivar o aluno para esta tarefa, procurouse criar uma situação de haver um castelo, no qual morava um esqueleto e, em certo momento, um fantasma chegou e abriu a porta. Além disso, os trabalhos dos alunos, especialmente os relacionados com a escrita, foram observados em sala de aula, tendo sido constatado que os mesmos guardaram relação com o obtido quando da aplicação da avaliação.

Considerando-se a produção como um todo, isto é, com as palavras e a frase componentes, caracterizou-se a escrita com base nas hipóteses de escrita propostas por Ferreiro e Teberosky (1999) pré-silábica, silábica, silábica-alfabética e alfabética.

Avaliação do componente fonológico da memória de trabalho

$\mathrm{Na}$ avaliação do componente fonológico da memória de trabalho, utilizou-se o subteste cinco de memória seqüencial auditiva, do Illinois Test of Psycholinguistic Abilities (ITPA), com adaptação brasileira de Bogossian e Santos (1977), e a prova de repetição de palavras sem significado (Anexo), elaborada por Kessler (1997), pois estes têm sido amplamente empregados em estudos recentes na literatura brasileira e estrangeira (Kessler, 1997; Linassi et al., 2001; Gindri et al., 2005).

O subteste cinco do ITPA consiste na repetição de 28 seqüências de dígitos, distribuídas de dois a sete dígitos, enunciados fora de ordem, com número variado de seqüências para cada quantidade de dígitos, imediatamente após o examinador enunciá- 
las. As seqüências foram apresentadas oralmente, em ritmo uniforme de dois dígitos por segundo. A soma dos pontos levou à obtenção do escore bruto, que foi convertido em escore escalar, de acordo com a faixa etária e correspondente à idade cronológica individual. O desempenho médio do grupo de referência equivale, para idade em estudo, ao escore de 36 pontos, podendo variar em seis pontos, para mais ou para menos. O escore escalar esperado variou entre 30 e 42 pontos. Além do escore escalar, foi realizada a análise do número máximo de dígitos repetidos corretamente.

O subteste cinco, memória seqüencial auditiva, foi realizado no início da avaliação de cada aluno, a fim de reduzir o efeito da fadiga.

A prova de repetição de palavras sem significado consiste na repetição de palavras formadas por seqüências fonológicas desprovidas de significado. Ela é composta por 30 palavras sem significado, constituídas por estrutura silábica simples, do tipo consoante-vogal, seguindo a estrutura fonológica do Português. As palavras são dispostas em seis listas, cada qual com cinco palavras sem significado, conforme o número de sílabas, que varia de uma a seis.

$\mathrm{Na}$ aplicação da referida prova, o aluno foi convidado a brincar de falar uma língua diferente, com palavras que ele não conhecia, mas deveria repetir, imediatamente, após o modelo. Nesta tarefa, o parâmetro considerado é de um ponto quando o aluno consegue repetir o item, tal qual foi apresentado. A tentativa é considerada incorreta quando o aluno omite, substitui, não produz nenhum fonema ou quando não consegue reproduzir o item, como este foi apresentado pelo examinador. Nestes casos, não é atribuído ponto. Na análise das respostas por lista, foi considerada aquela de maior número de sílabas, em que houve a repetição correta dos cinco itens.

\section{Avaliação da consciência fonológica}

Na avaliação da consciência fonológica, foi utilizado o teste consciência fonológica: instrumento de avaliação seqüencial (CONFIAS), elaborado por Moojen et al. (2003). O instrumento é composto por tarefas de síntese, segmentação, identificação, produção, exclusão e transposição silábica e fonêmica. A aplicação seguiu a proposta seqüencial de iniciar pelas tarefas que envolvem consciência da sílaba e, posteriormente, as que se referem ao nível do fonema, respeitando sua ordem. Para este estudo apenas foram utilizados os resultados em nível de sílaba, de fonema e total.

A pontuação do teste é realizada no protocolo de respostas. As respostas corretas valem um ponto e as incorretas valem zero. Na sílaba, o máximo de pontuação são 40 pontos e nos fonemas, o máximo são 30 , totalizando 70 pontos.

Após a coleta dos dados, os resultados foram tabulados e analisados, por meio de procedimento estatístico com uso do Software Estatístico SPSS versão 8.0 (Barbetta, 2003). O teste $x^{2}, \operatorname{com} p<0,001$, complementado pela análise de resíduos ajustados, $\operatorname{com} \mathrm{p}<0,05$, foi utilizado para verificar a associação entre o nível de hipótese de escrita dos alunos em relação à escolaridade. Os resultados obtidos quanto ao componente fonológico da memória de trabalho e à consciência fonológica foram analisados através do Teste T de Student, considerando-se $\mathrm{p}<0,001$.

\section{Resultados e Discussão}

O desempenho de alunos de pré-escola e primeira série quanto à hipótese de escrita são apresentados na Tabela 1 .

Verificou-se que os alunos de pré-escola estão localmente associados aos níveis de escrita présilábica e silábica e os de primeira série ao nível alfabético de escrita, havendo diferenças significativa entre os grupos quanto à hipótese de escrita (Tabela 1). Esta constatação encontra respaldo em Ferreiro e Teberosky (1999), pois a criança pode iniciar seus conhecimentos no mundo da escrita muito antes que qualquer tentativa formal de ensino seja proposta. Isto explica por que alunos de pré-escola estavam adiantados, em relação aos da primeira série, quanto à hipótese de escrita. Apesar de não estar recebendo instrução formal para aquisição da escrita, alfabetização, 11 préescolares mostravam aquisições quanto à escrita.

TABELA 1. Desempenho quanto à hipótese de escrita de alunos de préescola e primeira série.

\begin{tabular}{|c|c|c|c|c|c|c|}
\hline \multirow{3}{*}{ Hipótese de Escrita } & \multicolumn{4}{|c|}{ Escolaridade } & \multirow{2}{*}{\multicolumn{2}{|c|}{ TOTAL }} \\
\hline & \multicolumn{2}{|c|}{ Pré-Escola } & \multicolumn{2}{|c|}{ Primeira Série } & & \\
\hline & $\mathrm{n}$ & $\%$ & $\mathrm{n}$ & $\%$ & $\mathrm{n}$ & $\%$ \\
\hline nível pré-silábico & $29 *$ & 72,5 & 0 & 0,0 & 29 & 32,2 \\
\hline nível silábico & $5 *$ & 12,5 & 0 & 0,0 & 5 & 5,6 \\
\hline $\begin{array}{l}\text { nível silábico- } \\
\text { alfabético }\end{array}$ & 1 & 2,5 & 2 & 4,0 & 3 & 3,3 \\
\hline nível alfabético & 5 & 12,5 & $48^{*}$ & 96,0 & 53 & 58,9 \\
\hline TOTAL & 40 & 100,0 & 50 & 100,0 & 90 & 100,0 \\
\hline
\end{tabular}

$x^{2}=68,96 ; \mathrm{p}<0,001$

* Análise de resíduos ajustados: $\mathrm{p}<0,05$ 
Constatando que houve diferença significativa quanto à hipótese de escrita entre a pré-escola e a primeira série, concorda-se com Morgado (2005), aprendizagem e memória são processos complexos implicados entre si.

Para ser possível a comparação das médias de desempenho dos alunos de pré-escola e primeira série na avaliação do componente fonológico da memória de trabalho e de consciência fonológica quanto à hipótese de escrita, foram associados os níveis de escrita pré-silábico e silábico e os níveis silábicoalfabético e alfabético em função da distribuição da variável nível de escrita, porque se observaram poucos casos nos níveis silábico e silábicoalfabético. Os níveis pré-silábico e silábico de escrita mostraram-se associados à pré-escola e os níveis silábico-alfabético e alfabético, à primeira série.

O desempenho no componente fonológico da memória de trabalho, quanto à seqüência de dígitos, pontuação e escore escalar correspondentes, bem como número de sílabas e sua pontuação, em relação à hipótese de escrita dos alunos são mostrados na Tabela 2.

TABELA 2. Desempenho em memória de trabalho quanto à seqüência de dígitos, pontuação e escore escalar correspondentes e número de sílabas e sua pontuação, em relação à hipótese de escrita de alunos de pré-escola e primeira série.

\begin{tabular}{|c|c|c|c|c|c|c|c|c|c|}
\hline & \multicolumn{8}{|c|}{ Hipótese de Escrita } & \multirow{3}{*}{$\mathrm{P}$} \\
\hline & \multicolumn{4}{|c|}{ Pré-Silábico e Silábico } & \multicolumn{4}{|c|}{ Silábico-Alfabético e Alfabético } & \\
\hline & Média & Desvio-Padrão & Mínimo & Máximo & Média & Desvio-Padrão & Mínimo & Máximo & \\
\hline seqüência de dígitos & 4,80 & 0,61 & 4 & 6 & 5,06 & 0,55 & 4 & 6 & 0,036 \\
\hline pontuação em seqüência de dígitos & 21,95 & 5,23 & 11 & 34 & 24,86 & 4,32 & 16 & 35 & 0,005 \\
\hline $\begin{array}{c}\text { escore escalar em seqüência de } \\
\text { dígitos }\end{array}$ & 36,48 & 3,95 & 30 & 46 & 37,12 & 2,94 & 31 & 43 & 0,393 \\
\hline número de sílabas & 4,30 & 0,52 & 4 & 6 & 4,56 & 0,61 & 4 & 6 & 0,031 \\
\hline pontuação em número de sílabas & 21,50 & 2,58 & 20 & 30 & 22,80 & 3,06 & 20 & 30 & 0,031 \\
\hline
\end{tabular}

$\mathrm{p}<0,05$

Tanto os alunos de pré-escola como os de primeira série demonstraram capacidade de repetir seqüência de quatro a seis dígitos e de quatro a seis sílabas de palavras sem significado, embora a média dos resultados demonstre diferença significativa entre os dois níveis quanto aos testes, concordando com Miller(1956), Gathercole (1995) e Baddeley (2003).

Gindri et al. (2005) compararam o desempenho de pré-escola e primeira série quanto à memória de trabalho. Os alunos de pré-escola foram capazes de repetir seqüências de três a cinco dígitos e palavras sem significado com quatro a seis sílabas, enquanto os de primeira série repetiram seqüências de quatro a seis dígitos e palavras sem significado com quatro a seis sílabas. Os resultados do presente estudo são semelhantes. Concordam, ainda, com Kessler (1997) que, estudando pré-escolares, obteve média de repetição de seqüências de quatro dígitos e de quatro sílabas de palavras sem significado.

Observou-se expansão da capacidade de memória de trabalho com a idade, como propõe Baddeley (2003), que afirma que ela está relacionada com o aumento nas habilidades de fala e linguagem.

As diferenças observadas no desempenho médio entre os alunos de pré-escola e primeira série são significativas em favor dos alunos de primeira série, que são aqueles com idade superior e que apresentaram, em sua maioria, escrita alfabética, enquanto os alunos de pré-escola têm idade inferior e apresentaram, em sua maioria, escrita pré-alfabética.

O desempenho semelhante nas tarefas de repetição de dígitos e de sílabas sem significado corrobora a hipótese de que estas tarefas podem ser comparadas, como apontam Hulme et al. (1984), Adams e Gathercole (1995).

Alloway et al. (2004) propõem que os traços da memória de trabalho servem de importante base para representações mais duradouras de novas palavras. As relações entre memória de trabalho e conhecimento fonológico tornam-se mais complexas a partir dos cinco anos, como se observa na Tabela 2. 
Na Tabela 3, é apresentado o desempenho obtido pelos alunos em consciência fonológica com a aplicação CONFIAS, ao nível de sílaba, de fonema e total - em relação à hipótese de escrita.

Verificou-se que as médias dos aspectos avaliados de consciência fonológica através do CONFIAS é significativamente maior para os alunos de primeira série do que as médias dos alunos de pré-escola (Tabela 3). Este melhor desempenho dos alunos de primeira série está de acordo com Yavas (1989) que aponta o papel da escolaridade como favorecedor, dando conta dos progressos constatados com o início de alfabetização.

Os resultados das tarefas de consciência fonêmica e consciência silábica mostram que as habilidades de consciência fonológicas fazem parte do desenvolvimento contínuo, sendo que as tarefas que envolvem manipulação de sílabas precedem às que envolvem manipulação de fonemas (Cielo, 2002).

Houve diferença estatisticamente significativa nas habilidades de consciência entre as crianças de pré-escola e as de primeira série, concordando com Magnusson (1990) e Adams e Gathercole (1995) que afirmam que as habilidades fonológicas vinculamse ao desenvolvimento cognitivo. Os resultados também estão de acordo com os encontrados por Hulme et al. (1984); Roazzi e Dowker (1989) que as relacionam ao processo maturacional decorrente deste período. Acrescente-se que estas faixas etárias sofrem influência conjunta do tempo de escolaridade, o que favorece o desenvolvimento da consciência fonológica (Capellini e Ciasca, 2000; Capovilla et al., 2004).

As diferenças quanto à consciência fonológica, tanto em nível de sílaba quanto de fonema e no total de desempenho, podem ser explicadas pelo fato de alunos mais velhos (primeira série) estarem em contato com a alfabetização, tanto que demonstram este conhecimento estando em nível de escrita mais avançado (grande maioria em hipótese alfabética), concordando com Morais et al. (1989), Demont (1997) e Cielo (2002).

Os alunos com melhor desempenho nas habilidades de consciência são aqueles que também apresentam melhor desempenho em escrita (nível alfabético - primeira série), o que concorda com as propostas de Flores (1992), Gombert (1992)e Coimbra (1997), a consciência fonológica faz parte dos prérequisitos para aprendizagem da leitura e escrita.

A exposição formal à escrita, que ocorre durante a primeira série, evoca conhecimentos da escrita alfabética e favorece as habilidades de consciência fonêmica, como se observa na Tabela 3 . Anteriormente, a criança não necessita possuir conscientemente o conhecimento fonológico de que o fonema é uma unidade sonora, porque, para falar, isto não é necessário (Moojen et al., 2003; Santamaria et al., 2004). Evidencia-se que a introdução do sistema alfabético, que ocorre de maneira formal na primeira série, auxilia o desenvolvimento da consciência fonêmica (Maluf e Barrera, 1997; Lazzarotto e Cielo, 2002). O processo de escolarização é muito importante para o desenvolvimento do indivíduo, tendo em vista a relevância dos processos de aprendizagem no desenvolvimento das funções mentais superiores, $o$ que justifica o desempenho superior dos alunos de primeira série (Torgensen et al., 1994; Gindri et al., 2005).

As habilidades de memória de trabalho e consciência fonológica favorecem o desenvolvimento da alfabetização, segundo Mann e Llberman (1984), Santos e Siqueira (2002) e Morgado (2005), com o que concordam resultados da presente pesquisa, assim como o desenvolvimento destas habilidades tem inter-relação com a aprendizagem (Santos e Navas, 2002; Etchepareborda e Abad-Mas, 2005).

TABELA 3. Média e desvio-padrão, na avaliação de consciência fonológica ao nível de sílaba, de fonema e resultado total relação à hipótese de escrita de alunos de pré-escola e primeira série.

\begin{tabular}{|c|c|c|c|c|c|}
\hline \multirow{3}{*}{ Consciência Fonológica } & \multicolumn{4}{|c|}{ Hipótese de Escrita } & \multirow{3}{*}{$P$} \\
\hline & \multicolumn{2}{|c|}{ Pré-Silábico e Silábico } & \multicolumn{2}{|c|}{ Silábico-Alfabético e Alfabético } & \\
\hline & Média & Desvio-Padrão & Média & Desvio-Padrão & \\
\hline nível de sílaba & 18,44 & 3,85 & 30,82 & 5,25 & $<0,001$ \\
\hline nível de fonema & 7,35 & 2,62 & 16,11 & 4,81 & $<0,001$ \\
\hline TOTAL & 26,09 & 5,45 & 46,91 & 8,85 & $<0,001$ \\
\hline
\end{tabular}

$\mathrm{p}$ = nível mínimo de significância do Teste $\mathrm{T}$ de Student 


\section{Conclusão}

As habilidades de memória de trabalho e consciência fonológica se inter-relacionam e guardam dependência com a idade cronológica e conseqüente maturidade. Estas habilidades favorecem a aquisição inicial da escrita pelos alunos de pré-escola e primeira série, bem como sofrem influência dos estímulos provenientes da educação escolar.

\section{Anexo}

Prova de repetição de palavras sem significado (Kessler, 1997).

\begin{tabular}{|l|l|l|l|l|l|}
\hline Uma Sílaba & Emissão & Repetição & Quatro Sílabas & Emissão & Repetição \\
\hline 1. bó & ['bó] & & 1. palifemo & [pali'femu] & \\
\hline 2. lum & ['lũ] & & 2. romutega & [Romu'tega] & \\
\hline 3. rau & ['Raw] & & 3. pefisuni & [pefi'zuni] & \\
\hline 4. pin & ['pĩ] & & 4. morinati & [mori’nači] & \\
\hline 5. fe & ['fe] & & 5. jalopurti & [žalo'purči] & \\
\hline Duas Sílabas & & & Cinco Sílabas & & \\
\hline 1. dalu & ['dalu] & & 1. dojabefari & [dožabe'fari] & \\
\hline 2. leca & ['leka] & & 2. ranocidomi & [Ranosi'domi $\}$ & \\
\hline 3. nusa & ['nuza] & & 3. zalivemafu & [zalive'mafu] & \\
\hline 4. bunfe & ['bũfe] & & 4. gocipobilo & [gosipo'bilu] & \\
\hline 5. quewsi & ['kewsi] & & 5. agucafire & [aguka'fire] & \\
\hline Três Sílabas & & Seis Sílabas & & \\
\hline 1. quentagi & [ken'taži] & & 1. femorituzoli & [femoritu'zóli] & \\
\hline 2. belsifi & [bew'sifi] & & 2. alcabinteroca & [awkabĩte'róka] & \\
\hline 3. tonasso & [to'nasu] & & 3. zovibescofari & [zovibesko'fari] & \\
\hline 4. lanasi & [la'nazi] & & 4. gerobinfoquemi & [žerobĩfo'kemi] & \\
\hline 5. gamalo & [ga'malu] & & 5. chedizatocaro & [šežizato'karu] & \\
\hline
\end{tabular}

\section{Referências Bibliográficas}

ADAMS, A. M.; GATHERCOLE, S. E. Phonological working memory and speech production in preschool children. J. Speech Hear. Res., Washington, v. 38, n. 2, p. 403-414, apr. 1995.

ALlOWAY, T. P.; GATHERCOLE, S. E.; WILlis, C. E.; ADAMS, A. A structural analysis of working memory and related cognitive skills in young children. J. Experim. Child Psychol., Chicago, v. 7, n. 87, p. 85-106, jul. 2004.

BADDELEY, A. D. Working memory and language: an overview. J. Commun. Dis., Amsterdã, v. 36, n. 3, p. 189208, may.-jun. 2003.

BADDELEY, A. The episodic buffer: a new component of working memory? Trends Cognit. Sci., Kidlington, v. 4, n. 1, p. 417-423, nov. 2000.

BARBETTA, P. A. Estatística aplicada às ciências sociais. 5. ed. Florianópolis: UFSC, 2003.
BOGOSSIAN, M. A. D. S.; SANTOS, M. J. Adaptação brasileira: teste Illinois de habilidades psicolingüísticas. Florianópolis: Tamasa, 1977.

CAPELLINI, S. A.; CIASCA, S. M. Avaliação da consciência fonológica em crianças com distúrbio específico de leitura e escrita e distúrbio de aprendizagem. T. Desenv., São Paulo, v. 8, n. 48, p. 17-23, jan.-fev. 2000.

CAPOVIlla, A. G. S.; GÜTSCHOW, C. R. D.; CAPOVILLA, F. C. Habilidades cognitivas que predizem competência de leitura e escrita. Psicol.: Teor. Prát., São Paulo, v. 6, n. 2, p. 13-26, jul.-dez. 2004.

CIELO, C. A. Habilidades em consciência fonológica em crianças de 4 a 8 anos de idade. Pró-Fono R. Atual. Cient., Barueri, v. 14, n. 3, p. 301-312, set.-dez. 2002.

COIMBRA, M. A habilidade metafonológica em crianças de cinco anos. Letras Hoje, Porto Alegre, v. 32, n. 4, p. 61-79, dez. 1997. 
DEMONT, E. Consciência fonológica, consciência sintática: que papel (ou papéis) desempenha na aprendizagem eficaz da leitura? In: GREGÓIRE, J.; PIÉRART, B. (Orgs.). Avaliação dos problemas de leitura: os novos modelos teóricos e suas implicações diagnósticas. Porto Alegre: Artes Médicas, 1997. p. 189-201.

ETCHEPAREBORDA, M. C.; ABAD-MAS, L. Memoria de trabajo en los procesos básicos del aprendizaje. $R$. Neurol., Barcelona, v. 40, supl. 1, p. 79-83, jan. 2005.

FERREIRO, E. Escrita e oralidade: unidades, níveis de analise e consciência metalingüística. In: FERREIRO, E. (Org.). Relação de (in) dependência entre oralidade $e$ escrita. Porto Alegre: Artmed, 2004. cap. 8, p. 139-172. FERREIRO, E.; TEBEROSKY, A. Psicogênese da Língua Escrita. Porto Alegre: Artes Médicas do Sul, 1999. (Edição comemorativa dos 20 anos de publicação).

FLORES, O. C. Sensibilidade lingüística e aprendizagem inicial da leitura e da escritura. Letras Hoje, Porto Alegre, v. 1, n. 4, p. 46-63, dez. 1992.

GATHERCOLE, S. E. Is nonword repetition a test of phonological memory or long-term knowledge? It all depends on the nonwords. Mem. Cognit., Austin, v. 23, n. 1, p. 83-94, jan. 1995.

GINDRI, G.; KESKE-SOARES, M.; MOTA, H. B. Comparação do desempenho de crianças pré-escolares e de primeira série em tarefas envolvendo a memória de trabalho. R. Soc. Bras. Fonoaudiol., São Paulo, v. 10, n. 4, p. 201-206, out.-dez. 2005.

GOMBERT, J. E. Metalinguistic development. Chicago: University of Chicago Press, 1992.

HERNANDORENA, C. L. M.; LAMPRECHT, R. R. A aquisição das consoantes líquidas do português. Letras Hoje, Porto Alegre, v. 32, n. 4, p. 7-22, dez. 1997.

HULME, C.; THOMSON, C. M.; LAWRENCE, A. Speech rate and the development of short-term memory span. $J$. Experim. Child Psychol., New York, v. 38, n. 2, p. 241253, oct. 1984.

KESSLER, T. M. Estudo da memória operacional em préescolares. 1997. 36 f. Dissertação (Mestrado em Distúrbios da Comunicação Humana) - Universidade Federal de Santa Maria, Santa Maria.

LAZZAROTTO, C.; CIELO, C. A. Consciência fonológica e sua relação com a alfabetização. R. Soc. Bras. Fonoaudiol., São Paulo, v. 7, n. 2, p. 15-24, abr.-jun. 2002.

MALUF, M. R; BARRERA, S. D. Consciência fonológica e linguagem escrita em pré-escolares. Psicol.: Refl. Crít., Porto Alegre, v. 10, n. 1, p. 125-145, jan. 1997.

MANN, V. A.; LLBERMAN, I. Y. Phonological awareness and verbal short-term memory. J. Lear. Disab., Chicago, v. 17, n. 10 , p. $592-599$, dec. 1984.
MAGNUSSON, E. Consciência metalingüística em crianças com desvios fonológicos evolutivos. In: YAVAS, M. Desvios fonológicos em crianças. Porto Alegre: Mercado Aberto, 1990. cap. 5, p. 109-148.

MARCHESAN, I. Q. Fundamentos em fonoaudiologia: aspectos clínicos da motricidade oral. 2. ed. Rio de Janeiro: Guanabara Koogan, 2005.

MILLER, G. The magical number seven, plus or minus two: some limits on our capacity for processing information. Psychol. Rev., Washington, v. 63, p. 81-97, 1956.

MOOJEN, S.; LAMPRECHT, R. R.; SANTOS, R. M.; FREITAS, G. M.; BRODACZ, R.; SIQUEIRA, M.; CORREA, A.; GUARDA, E. CONFIAS - Consciência Fonológica: Instrumento de Avaliação Seqüencial. São Paulo: Casa do Psicólogo, 2003.

MORAIS, J.; KOLINSKY, R.; ALÉGRIA, J.; SCLIARCABRAL, L. Alphabetic literacy and psychological structure. Letras Hoje, Porto Alegre, v. 33, n. 4, p. 61-79, dez. 1998.

MORALES, M. V.; MOTA, H. B.; KESKE-SOARES, M. Consciência fonológica: desempenho de crianças com e sem desvios fonológicos evolutivos. Pró-Fono R. Atual. Cient., Carapicuíba (SP), v. 14, n. 2, p. 153-164, maio.ago. 2002.

MORGADO, I. Psicología del aprendizaje y la memoria: fundamentos y avances recientes. R. Neurol., Barcelona, v. 40, n. 5, p. 289-197, mar. 2005.

NORTHERN, J. L.; DOWNS, M. P. Audição em crianças. 3. ed. São Paulo: Manole, 1989.

OAKHILL, J.; KYLE, F. The relations between phonological awareness and working memory. J. Experim. Child Psycol., New York, v. 75, n. 2, p. 152-164, feb. 2000.

ROAZZI, A.; DOWKER, A. Consciência fonológica, rima e aprendizagem da leitura. Psicol.: Teor. Pesq., Brasília, v. 5, n. 1, p. 31-55, jan.-abr. 1989.

SANTAMARIA, V. L.; LEITÃO, P. B.; ASSENCIOFERREIRA, V. J. A consciência fonológica no processo de alfabetização. R. Cefac, São Paulo, v. 6, n. 3, p. 237-241, jul.-set. 2004.

SANTOS, M. R.; SIQUEIRA, M. Consciência fonológica e memória. R. Fono Atual, São Paulo, v. 5, n. 20, p. 4853, jun. 2002.

SANTOS, M. T. M.; NAVAS, A. L. P. Terapia da linguagem escrita. In: Distúrbios de leitura e escrita: teoria e prática. Barueri: Manole, 2002. cap. 6, p. 191-223.

TORGESEN, J. K.; WAGNER, R. K.; RASHOTTE, C. A. Longitudinal studies of phonological processing and reading. J. Lear. Disab., Chicago, v. 27, n. 5, p. 276-286, may 1994.

YAVAS, F. Habilidades metalingüísticas na criança: uma visão geral. Cad. Est. Ling., Campinas, n. 14, p. 39-51, jan.-jun. 1989. 